\title{
Particulated microalgae composite (PMC) as substitute for live microalgae in culture of juvenile Manila clam Ruditapes philippinarum (A. Adams and Reeve, 1850): A feasibility analysis
}

\author{
JIAN LIANG, XIANGDONG BI, WEI DAI ${ }^{1}$ AND YUEWEN DENG* \\ Tianjin Key Laboratory of Aqua-ecology and Aquaculture, Fisheries College, Tianjin Agricultural University \\ Tianjin - 300 384, China \\ *Pearl Breeding and Processing Engineering Technology Research Centre of Guangdong Province, Fisheries College \\ Guangdong Ocean University, Zhanjiang - 524 088, China \\ e-mail:yl801123@aliyun.com
}

\begin{abstract}
To evaluate the feasibility of particulated microalgae composite (PMC) as live microalgae substitute in artificial breeding of Manila clam Ruditapes philippinarum, effects of replacing Dicrateria inornata with partial or total PMC on the growth, digestive enzyme activities, nutritional ingredient composition and microbial composition in faeces of juvenile clams were investigated. The results showed that 50 and 100\% PMC replacement did not affect the mean shell length, mean body weight and survival rate of juvenile clams ( $p>0.05$ ). Juvenile clams fed with $100 \%$ PMC replacement had higher lipase and pepsin activities than those fed with $100 \%$ D. inornata $(\mathrm{p}<0.05)$, while $50 \%$ PMC replacement only increased lipase activity $(\mathrm{p}<0.05)$. Essential amino acid (EAA) and polyunsaturated fatty acid (PUFA) contents exhibited no obvious differences between clams fed with and without PMC replacement ( $p>0.05)$. Significant increase in delicious amino acid contents $(\mathrm{p}<0.05)$ was observed with $100 \%$ PMC replacement. PMC replacement did not affect the diversity of dominant phyla in faeces, but the abundance of each dominant phylum. Similar relative abundance of faecal bacteria was observed when D. inornata was replaced with 50 and $100 \%$ PMC. PMC appeared to be a potential substitute for microalgae in artificial Manila clam breeding.
\end{abstract}

Keywords: Dicrateria inornata, Microalgae substitute, Particulated microalgae composite, Ruditapes philippinarum

\section{Introduction}

The Manila clam Ruditapes philippinarum (A. Adams and Reeve, 1850), is one of the major aquaculture species in Asian, American and European countries (Liang et al., 2019). In China, aquaculture of $R$. philippinarum developed rapidly in coastal areas of the Yellow Sea, Bohai Sea and East Sea since the 1990s (Fang and Lin, 2016). The annual production of this species in China is as high as 3.97 million $t$, accounting for about $27.57 \%$ of the national shellfish production in 2019 (Yu et al., 2020). In the traditional culture methods of Manila clam, the seeds needed for aquaculture were mainly collected from intertidal zones. However, the harvesting of wild seeds is always uncontrollable, seasonally restricted and labour intensive. Developing artificial breeding technology can increase the stability of seed supply and shorten the production cycle, leading to increased production and profit of Manila clam farming. In China, mass breeding technology with short production cycle has been developed in the hatchery (Zhang et al., 2006).

Manila clam is a filter-feeding bivalve and mainly feeds on live microalgae in seawater. Seed production of filter-feeding bivalves in the hatcheries relies heavily on live microalgae production. Therefore, sufficient microalgae culture is an important prerequisite in artificial breeding of Manila clam. However, the culture of microalgae is costly and often unpredictable (Pettersen et al., 2010) and the production in large quantities is often accompanied by various technical difficulties. Culturing adequate microalgae to meet daily feeding requirement of clam has become a heavy burden to many hatcheries. In some hatcheries of China, juvenile Manila clams have to be transferred to the mudflat to grow-out until they reach market-size seed, although juvenile clam is especially vulnerable to environmental challenge in the entire breeding cycle (Huo et al., 2018). Therefore, in Manila clam seed production, alternative food sources are needed. The partial or total replacement of microalgal foods with a cost-effective and easy to handle substitute, such as dried algae diet (Laing et al., 1990), microalga detritus (Yin et al., 2019), concentrated algal pastes (Ponis et al., 2008), dietary lipid emulsion (Ehteshami et al., 2016), baker's yeast (Tanyaros et al., 2016) and microencapsulated diets (Willer and Aldridge, 2017), 
have been attempted for the artificial breeding of clam. In addition to being cost-effective and easy to handle, there are many other requirements associated with the development of microalgae substitute. These diets must have the equivalent nutrient value and need to be easily digested and assimilated. Moreover, substitute diets need to remain in suspension because deposition easily cause bacterial contamination.

In this study, we developed particulated microalgae composite (PMC) with dried microalgae and fermented soybean meal as the main ingredients. To assess the feasibility of PMC as substitute for live microalgae in the culture of juvenile manila clam, we investigated the effects of PMC replacement on the growth, survival rate, digestive enzyme activity and nutritional ingredient composition as well as bacterial diversity in the faeces of juvenile clams.

\section{Materials and methods}

\section{PMC preparation}

The main ingredients of PMC comprised spray-dried Chlorella vulgaris, Spirulina platensis powder and fermented soybean meal which were smashed to particle size below $20 \mu \mathrm{m}$ with HMB-20-S water-cooled pulveriser and then mixed with a mass ratio of 4.5:4.5:1 to prepare composite algal powder. Composite algal powder, granular sodium alginate and $2 \%$ calcium chloride solution were mixed at a mass ratio of 25:5:1.25 and stirred well, then injected into a hydraulic press to obtain block-shaped compound feed $(4 \times 4 \times 2.5 \mathrm{~cm})$ at a pressure of $87.5 \mathrm{~kg} \mathrm{~cm}^{2}$. Before feeding, feed block was weighed, introduced into a 500 -mesh bag and scrubbed to particulates in sand-filtered seawater.

\section{Organisms and cultivation}

R. philippinarum juveniles were provided by Haisheng Aquaculture Co. Ltd. of Tianjin, China. After being sieved through 4 and $6 \mathrm{~mm}$ mesh sieves sequentially, juvenile clams were unfed for 7 days in constantly aerated sand-filtered seawater. The rearing seawater was refreshed daily and the dissolved oxygen was maintained above $5 \mathrm{mg} \mathrm{l}^{-1}$, salinity fluctuated from 29 to $31 \mathrm{ppt}$ and temperature ranged from 24 to $26^{\circ} \mathrm{C}$.

Dicrateria inornate, the most common algal species used in Manila clam culture, was obtained from Institute of Oceanology, Chinese Academy of Sciences. D. inornata was cultured in F2 medium (Guillard, 1974) at $25 \pm 2{ }^{\circ} \mathrm{C}$ under natural illumination. When $D$. inornata cells reached the late logarithmic phase (approximately $5 \times 10^{6}$ nos. $\mathrm{ml}^{-1}$ ), culture medium was harvested and used to feed juvenile clams directly.

\section{Experimental design}

About 9000 juvenile clams (mean shell length $5.02 \pm 0.37 \mathrm{~mm}$, mean body weight $0.0261 \pm 0.0152 \mathrm{~g}$, $\mathrm{n}=40$ ) were randomly divided into three groups with three replicate tanks. Each tank $(34.5 \times 24 \times 10.5 \mathrm{~cm})$ was filled with 61 sand-filtered seawater or D. inornata culture medium. Clams were fed with different diets (Table 1) twice daily at 6:00 and 18:00 hrs for 28 days. In hatcheries, D. inornata culture medium in the late logarithmic phase were directly used to culture juvenile Manila clam. Clams cultured in D. inornata culture medium (approximately $5 \times 10^{6}$ cells $\mathrm{ml}^{-1}$ ) were treated as control. Before feeding, the cell density of $D$. inornata was measured under a microscope and the dry weight of $D$. inornata in 61 culture medium was estimated. PMC replaced the same dry weight of $D$. inornata at 50 and $100 \%$ ration in the other two treatments. Before each feeding, 100\% seawater was exchanged to remove the remaining diet. During the experimental period, salinity ranged from 28 to $32 \mathrm{ppt}$ and water temperature ranged from 23.8 to $28.2^{\circ} \mathrm{C}$. Growth, survival rate, digestive enzyme activity and nutritional ingredients of clams were measured at the end of the experiment. The deposited faecal matter were siphoned out before water exchange every 7 days. The faecal samples were filtered with $0.45 \mu \mathrm{m}$ filter and stored at $-20^{\circ} \mathrm{C}$ before the bacterial diversity was analysed.

\section{Growth performance}

At day 28, forty juveniles from each replicate tank were randomly sampled to record shell length (antero-posterior axis parallel to the hinge) with vernier caliper to the nearest $0.01 \mathrm{~mm}$ and to measure body weight using an electronic scale with accuracy of $0.0001 \mathrm{~g}$. Water on the surface of clams was removed using filter paper to minimise measurement errors. Dead clams were picked out and counted before feeding. Clams were considered dead when the shell opened and did not respond to touch.

\section{Collection of tissue samples}

The whole soft tissues of calms were sampled after being starved for $12 \mathrm{~h}$. All tissue samples were frozen in liquid nitrogen for more than $15 \mathrm{~min}$ and then stored at $-80^{\circ} \mathrm{C}$ for subsequent analysis.

Table 1. The proportion of $D$. inornate and PMC in the experiment diets

\begin{tabular}{lll}
\hline \multirow{2}{*}{ Treatment } & \multicolumn{2}{l}{ Composition of different diets per day } \\
\cline { 2 - 3 } & D. inornata & PMC \\
\hline D. inornata & $100 \%$ & - \\
D. inornata + PMC & $50 \%$ & $50 \%$ \\
PMC & - & $100 \%$ \\
\hline
\end{tabular}




\section{Digestive enzyme activity analysis}

For enzyme activity determination, approximately $0.2 \mathrm{~g}$ soft tissues were homogenised in $1.8 \mathrm{ml}$ ice-cold physiological saline, then centrifuged $\left(4^{\circ} \mathrm{C}, 2500 \mathrm{rpm}\right.$, $10 \mathrm{~min})$. Lipase, amylase and pepsin activities of the supernatant were evaluated using commercial assay kits (Jiancheng Bioengineering Institute, Nanjing, China) following the manufacturer's instructions. Total protein content of supernatant was assayed according to Bradford (1976) using bovine serum albumin as a standard.

\section{Nutritional ingredient analysis}

After acid hydrolysis according to the method of Dai et al. (2014), the total amino acids (AA) were determined by a liquid chromatograph (Waters ACQUITY UPLC I-CLASS, Waters) and mass spectrometer (Xevo TQ-XS, Waters) integrated with a column (BEH Amide $1.7 \mu \mathrm{M}$ $100 \times 2.1 \mathrm{~mm})$. Total lipid was extracted by sonication in dichloromethane-methanol $(2: 1, \mathrm{v} / \mathrm{v})$ according to the method of Yin et al. (2019) and the extracted lipids were esterified with $0.5 \mathrm{M} \mathrm{KOH}$ methanol. Fatty acid methyl esters (FAME) were analysed using a Phillips PU 4410 gas chromatograph equipped with a fused silica capillary column (BPX-70; $25 \mathrm{~m} \times 0.32 \mathrm{~mm} \times 0.25 \mu \mathrm{m}$ film) and FID detector.

\section{Faecal bacterial diversity analysis}

The genomic DNA of faecal bacteria was extracted using CTAB protocol and examined by agarose gel electrophoresis. PCR amplification and sequencing of the V4 region of bacterial 16S rRNA gene were conducted according to the method of $\mathrm{Bi}$ et al. (2019). PCR amplifications were performed with Phusion ${ }^{\circledR}$ High-Fidelity PCR Master Mix (New England Biolabs) and the primers used were 515F (5'-GTGCCAGCMG CCGCGGTAA-3') and 806R (5'-GGACTACHVGGG TWTCTAAT-3') (Caporaso et al., 2011). The same volume of $1 \times$ loading buffer (containing SYB green) was mixed with PCR products and detected by $2 \%$ agarose gel electrophoresis. PCR products of $400-450 \mathrm{bp}$ were selected and purified using Qiagen Gel Extraction Kit (Germany). TruSeq ${ }^{\circledR}$ DNA PCR-Free Sample Preparation Kit (Illumina, USA) was used to generate sequencing libraries and index codes were added. The library quality was evaluated using the Qubit ${ }^{\circledR}$ 2.0 Fluorometer (Thermo Scientific) and Agilent Bioanalyzer 2100 system. Finally, $250 \mathrm{bp}$ paired-end reads were obtained after using the NovaSeQ6000 platform to sequence the library.

Paired-end reads were allocated based on the unique barcode of the sample and truncated by cutting off the barcode and primer sequence. Paired-end reads were merged using FLASH (V1.2.7) (Magoc and Salzberg,
2011). According to the Qiime (V1.9.1) quality controlled procedure (Caporaso et al., 2010), the raw tags were quality-filtered under specific filtering conditions to obtain high-quality clean tags (Bokulich et al., 2013). To detect chimera sequences, the tags were compared with Gold database using UCHIME Algorithm (Edgar et al., 2011) and then removed the chimera sequences (Haas et al., 2011) and obtained the effective tags. Sequence analysis was performed using Uparse v7.0.1001 software (Edgar, 2013). Sequences with similarity $\geq 97 \%$ were allocated to the same OTUs. A representative sequence of each OTU was screened for further annotation. For each representative sequence, the GreenGene Database (Desantis et al., 2006) based on the RDP classifier (Version 2.2) (Wang et al., 2007) algorithm was used to annotate taxonomic information. To investigate the phylogenetic relationship of different OTUs and the difference of the dominant species in different groups, we performed multiple sequence alignment using the MUSCLE software (ver.) (Edgar, 2004). OTU abundance information was normalised using a standard of sequence number corresponding to the sample with the least sequences. All sequences were submitted to NCBI-GenBank (Acc. No. SRP321001).

\section{Statistical analysis}

Data are expressed as means \pm SD and were subjected to one-way analysis of variance (ANOVA, SPSS ver. 21.0) to determine significant differences between treatments. The significance of variation $(\mathrm{p}<0.05)$ was determined by least significant difference multiple-range test.

\section{Results}

\section{Growth performance}

As shown in Table 2, the mean shell length of clams fed with 50 and 100\% PMC replacement did not significantly differ from those fed with $100 \%$ D. inornata $(\mathrm{p}>0.05)$. There was no significant difference in the mean body weight of clams fed with 50 and 100\% PMC replacement and those fed with $100 \%$ D. inornata $(\mathrm{p}<0.05)$. Replacing 50 and $100 \%$ of D. inornata with PMC did not affect the survival rate significantly $(\mathrm{p}>0.05)$.

\section{Digestive enzyme activity}

Effects of PMC replacement on the digestive enzyme activities of $R$. philippinarum juveniles are shown in Table 3. Clams fed with 50 and 100\% PMC replacement had higher lipase activity than those fed with $100 \%$ D. inornata $(\mathrm{p}<0.05)$, while PMC replacement did not affect amylase activity significantly $(\mathrm{p}>0.05)$. Pepsin activity of clams fed with $100 \%$ D. inornata did not differ from those fed with 50\% PMC replacement ( $p>0.05$ ), but was significantly lower than those fed with $100 \%$ PMC replacement $(\mathrm{p}<0.05)$. 
Table 2. Effects of PMC replacement on the growth performance and survival rate of $R$. philippinarum juveniles

\begin{tabular}{llll}
\hline Parameter & D. inornata & D. inornata + PMC & PMC \\
\hline Shell length (mm) & $6.04 \pm 0.39$ & $6.32 \pm 0.36$ & $6.26 \pm 0.50$ \\
Body weight (g) & $0.0388 \pm 0.009$ & $0.0473 \pm 0.017$ & $0.0399 \pm 0.005$ \\
Survival (\%) & $78.53 \pm 0.83$ & $77.33 \pm 3.30$ & $74.33 \pm 4.41$ \\
\hline
\end{tabular}

Values are represented as means \pm SD. values sharing no letters are not significantly different $(\mathrm{p}>0.05)$.

\section{Amino acid composition}

The amino acid composition of juvenile clams fed with different diets are shown in Table 4. Replacing 50 and $100 \% D$. inornata with PMC could significantly increase glutamine contents $(\mathrm{p}<0.05)$. Proline, serine, tyrosine and glycine contents of clams fed with $100 \%$ PMC replacement were higher than those fed with $100 \%$ D. inornata $(\mathrm{p}<0.05)$ while no difference in these amino acid contents was observed between clams fed with 50\% PMC replacement and $100 \%$ D. inornata. Clams fed with $50 \%$ PMC replacement had higher $\gamma$-aminobutyric acid contents than those fed with $100 \%$ D. inornata $(\mathrm{p}<0.05)$ and there was no difference between clams fed with $100 \%$
Table 3. Effects of PMC replacement on the digestive enzyme activities ( $\mathrm{U} \quad \mathrm{mg}$ of protein $^{-1}$ ) of $R$. philippinarum juveniles

\begin{tabular}{llll}
\hline Parameter & D. inornata & D. inornata + PMC & PMC \\
\hline Lipase & $1.07 \pm 0.42^{\mathrm{b}}$ & $3.06 \pm 1.49^{\mathrm{a}}$ & $4.71 \pm 1.08^{\mathrm{a}}$ \\
Amylase & $0.04 \pm 0.01$ & $0.04 \pm 0.001$ & $0.08 \pm 0.06$ \\
Pepsin & $0.26 \pm 0.13^{\mathrm{b}}$ & $0.83 \pm 0.53^{\mathrm{ab}}$ & $1.01 \pm 0.38^{\mathrm{a}}$ \\
\hline
\end{tabular}

Values are represented as means \pm SD. Values sharing the same letters or no letters are not significantly different $(\mathrm{p}>0.05)$, whereas those with different letters are significantly different $(\mathrm{p}<0.05)$.

D. inornata and 100\% PMC replacement. Replacing $100 \%$ D. inornata with PMC could significantly increase delicious amino acid (DAA) contents $(\mathrm{p}<0.05)$. Free amino acid (FAA), essential amino acid (EAA) and non-essential amino acid (NEAA) contents exhibited no obvious differences between clams fed with and without PMC replacement $(\mathrm{p}>0.05)$.

\section{Fatty acid composition}

The fatty acid profiles of $R$. philippinarum in three groups are presented in Table 5. The primary components

Table 4. Effects of PMC replacement on free amino acid composition of $R$. philippinarum juveniles ( $\mu \mathrm{g} g$ wet $^{\text {weight }}{ }^{-1}$ )

\begin{tabular}{|c|c|c|c|}
\hline Amino acid & D. inornata & D. inornata $+\mathrm{PMC}$ & PMC \\
\hline Alanine\# & $322.21 \pm 100.53$ & $397.13 \pm 30.89$ & $408.27 \pm 104.75$ \\
\hline Arginine & $253.42 \pm 56.09$ & $264.75 \pm 64.04$ & $324.43 \pm 170.37$ \\
\hline Asparagine & $43.32 \pm 15.74$ & $47.30 \pm 6.61$ & $57.08 \pm 16.11$ \\
\hline Aspartic acid\# & $272.39 \pm 134.58$ & $339.49 \pm 64.11$ & $413.43 \pm 19.78$ \\
\hline Glutamine & $49.23 \pm 19.02^{\mathrm{b}}$ & $90.93 \pm 29.24^{\mathrm{a}}$ & $93.27 \pm 25.59^{\mathrm{a}}$ \\
\hline Glutamate\# & $240.94 \pm 40.81$ & $341.02 \pm 97.05$ & $299.08 \pm 48.02$ \\
\hline Histidine $^{*}$ & $43.40 \pm 22.01$ & $36.74 \pm 0.06$ & $45.96 \pm 10.08$ \\
\hline Isoleucine ${ }^{*}$ & $84.84 \pm 44.84$ & $85.94 \pm 38.64$ & $98.06 \pm 20.50$ \\
\hline Leucine $^{*}$ & $108.20 \pm 33.77$ & $133.13 \pm 37.62$ & $187.52 \pm 93.10$ \\
\hline Lysine $^{*}$ & $200.83 \pm 53.66$ & $197.35 \pm 118.84$ & $228.83 \pm 71.20$ \\
\hline Methionine* & $55.26 \pm 28.80$ & $63.59 \pm 22.26$ & $62.57 \pm 9.90$ \\
\hline Phenylalanine ${ }^{*}$ & $71.41 \pm 43.70$ & $94.37 \pm 24.03$ & $86.43 \pm 5.78$ \\
\hline Proline & $47.75 \pm 28.55^{\mathrm{b}}$ & $72.41 \pm 8.15^{\mathrm{b}}$ & $116.94 \pm 32.88^{\mathrm{a}}$ \\
\hline Serine & $112.33 \pm 20.21^{\mathrm{b}}$ & $157.92 \pm 41.75^{\mathrm{b}}$ & $242.32 \pm 69.77^{\mathrm{a}}$ \\
\hline Threonine* & $90.53 \pm 50.80$ & $142.24 \pm 48.38$ & $101.00 \pm 27.14$ \\
\hline Tryptophan* & $17.73 \pm 6.71$ & $15.90 \pm 7.06$ & $19.80 \pm 4.68$ \\
\hline Tyrosine & $63.58 \pm 6.28^{\mathrm{b}}$ & $57.20 \pm 27.04^{\mathrm{b}}$ & $99.72 \pm 17.49^{\mathrm{a}}$ \\
\hline Valine $^{*}$ & $130.61 \pm 111.40$ & $137.26 \pm 60.39$ & $148.07 \pm 13.93$ \\
\hline Taurine & $1391.58 \pm 615.56$ & $1636.17 \pm 493.24$ & $937.12 \pm 419.98$ \\
\hline Ornithine & $42.21 \pm 15.93$ & $48.31 \pm 26.84$ & $39.34 \pm 6.06$ \\
\hline Glycine\# & $315.12 \pm 215.89^{b}$ & $649.65 \pm 161.86^{\mathrm{ab}}$ & $720.50 \pm 284.88^{\mathrm{a}}$ \\
\hline$\gamma$-aminobutyric acid & $0.82 \pm 0.34^{\mathrm{b}}$ & $1.73 \pm 0.74^{\mathrm{a}}$ & $0.91 \pm 0.51^{\mathrm{ab}}$ \\
\hline Protein $(\%)$ & $9.27 \pm 0.24^{\mathrm{a}}$ & $8.79 \pm 0.53^{\mathrm{ab}}$ & $7.89 \pm 0.45^{\mathrm{b}}$ \\
\hline FAA & $3966.96 \pm 1393.70$ & $5019.39 \pm 718.71$ & $4738.56 \pm 883.21$ \\
\hline EAA & $802.80 \pm 328.68$ & $906.51 \pm 222.13$ & $978.25 \pm 145.55$ \\
\hline NEAA & $3154.90 \pm 1065.14$ & $4103.99 \pm 682.06$ & $3752.43 \pm 770.78$ \\
\hline DAA & $1150.67 \pm 466.46^{\mathrm{b}}$ & $1727.28 \pm 320.35^{\mathrm{ab}}$ & $1841.28 \pm 422.00^{\mathrm{a}}$ \\
\hline EAA/FAA (\%) & $19.98 \pm 1.18$ & $18.20 \pm 4.76$ & $20.79 \pm 2.08$ \\
\hline EAA/NEAA (\%) & $25.06 \pm 1.83$ & $22.57 \pm 7.18$ & $26.37 \pm 3.32$ \\
\hline
\end{tabular}

Values are represented as means $\pm \mathrm{SD}$. Values sharing the same letters are not significantly different $(\mathrm{p}>0.05)$, whereas those with different letters are significantly different ( $\mathrm{p}<0.05$ ). FAA: Free amino acids; EAA: Essential amino acids $(*)$; NEAA: Nonessential amino acids; DAA: Delicious or flavour amino acids (\#) 
of fatty acids in groups fed with 50 and 100\% PMC replacement were C22:6n-3(DHA), C20:2, C16:0 and C18:2n-6c. In group fed with 100\% D. inornata, C22:6n-3 (DHA), C20:4n-6(ARA), C20:5n-3(EPA) and C16:0 were the primary components of fatty acids. The contents of C11:0, C16:0, C23:0, C18:1n-9c, C18:2n-6c, C18:3n-6 and $\mathrm{C} 20: 2$ in clams fed with 50 and 100\% PMC replacement were higher than those fed with $100 \%$ D. inornata $(\mathrm{p}<0.05)$, while higher $\mathrm{C} 14: 0$ content was found in clams fed with $100 \%$ D. inornata $(\mathrm{p}<0.05)$. There was no significant difference in C22:6n-3(DHA) content between groups fed with $100 \%$ D. inornata and 50\% PMC replacement $(\mathrm{p}>0.05)$, while clams fed with 100\% PMC replacement showed lower C22:6n-3(DHA) content than those fed with $100 \% D$. inornata $(\mathrm{p}<0.05)$. No difference was observed in $\sum$ PUFA and $\sum$ SFA contents between three groups and clams fed with $100 \%$ PMC replacement showed higher $\sum$ MUFA content than those fed with $100 \%$ D. inornata $(\mathrm{p}<0.05)$. $\sum \mathrm{n}-3 / \sum \mathrm{n}-6$ value decreased with increased PMC replacement.

\section{Bacterial diversity in the faeces}

The bacterial profiles of the 36 samples analysed generated 48 distinctive bacterial phyla. Taxonomic composition of the faecal microbiota at phylum level among 3 diet groups was compared based on the mean of the relative abundance (Fig. 1). R. philippinarum in 3 diet groups had similar top 10 phyla, including Proteobacteria, Bacteroidetes, Actinobacteria, Verrucomicrobia, Firmicutes, Planctomycetes, Acidobacteria and Chloroflexi besides unidentified bacteria and unidentified archaea. However, the relative abundance of top 10 phyla varied greatly among 3 diet groups. Proteobacteria was the first dominant phylum in all the 3 diet groups. The relative abundance of Proteobacteria fed with $100 \%$ D. inornate, $50 \%$ D. inornate $+50 \% \mathrm{PMC}$ and $100 \% \mathrm{PMC}$ varied from 59.43 to $67.65 \%, 65.18$ to $79.04 \%$ and 63.39 to $84.69 \%$, respectively. Bacteroidetes, the second dominant phylum in all the 3 diet groups, represented $13.18-25.01 \%(100 \%$ D. inornate), $15.85-19.96 \%(50 \% \quad$ D. inornate $+50 \%$ PMC) and 10.23-25.83\% (100\% PMC) of all sequences. Function of faecal bacteria was predicted and the relative abundance of functional annotations in 3 diet groups is presented in Fig. 2. Similar relative abundant functions were observed in 3 diet groups. The relative abundance of metabolism, including amino acid, carbohydrate, energy, lipid and metabolism of cofactors and vitamins was nearly $50 \%$ in all 3 diet groups.

Table 5. Effects of PMC replacement on fatty acid composition of $R$. philippinarum juveniles ( $\mu \mathrm{g} g$ wet $^{\text {weight }}{ }^{-1}$ )

\begin{tabular}{|c|c|c|c|}
\hline Fatty acid & D. inornata & D. inornata+PMC & PMC \\
\hline C11:0 & - & $0.04 \pm 0.07$ & $0.02 \pm 0.03$ \\
\hline C12:0 & $0.31 \pm 0.03$ & $0.37 \pm 0.23$ & $0.33 \pm 0.11$ \\
\hline C14:0 & $12.67 \pm 1.65^{\mathrm{a}}$ & $5.60 \pm 1.78^{b}$ & $3.12 \pm 0.44^{\mathrm{b}}$ \\
\hline $\mathrm{C} 15: 0$ & $3.84 \pm 0.60$ & $3.01 \pm 1.72$ & $3.42 \pm 0.87$ \\
\hline C16:0 & $85.74 \pm 20.23^{b}$ & $126.80 \pm 72.26^{\mathrm{a}}$ & $162.08 \pm 29.84^{\mathrm{a}}$ \\
\hline $\mathrm{C} 17: 0$ & $25.94 \pm 1.60$ & $26.47 \pm 11.41$ & $27.81 \pm 5.80$ \\
\hline C18:0 & $68.94 \pm 7.87$ & $71.37 \pm 40.60$ & $83.60 \pm 17.14$ \\
\hline C20:0 & $33.31 \pm 1.95$ & $33.19 \pm 1.40$ & $33.85 \pm 2.36$ \\
\hline $\mathrm{C} 23: 0$ & $0.66 \pm 0.22^{\mathrm{b}}$ & $1.81 \pm 0.52^{\mathrm{a}}$ & $2.27 \pm 0.69^{\mathrm{a}}$ \\
\hline $\mathrm{C} 24: 0$ & $0.73 \pm 0.06$ & $0.73 \pm 0.36$ & $0.64 \pm 0.06$ \\
\hline C16:1 & $26.00 \pm 8.30$ & $17.45 \pm 4.11$ & $15.17 \pm 2.70$ \\
\hline C18:1n-9c & $56.88 \pm 14.05^{\mathrm{b}}$ & $105.20 \pm 23.93^{\mathrm{a}}$ & $117.91 \pm 18.17^{\mathrm{a}}$ \\
\hline$C 18: 2 n-6 c$ & $21.37 \pm 4.37^{\mathrm{c}}$ & $119.58 \pm 42.53^{b}$ & $190.93 \pm 28.59^{\mathrm{a}}$ \\
\hline C18:3n-6 & - & $19.33 \pm 13.18^{\mathrm{b}}$ & $46.57 \pm 5.56^{\mathrm{a}}$ \\
\hline C18:3n-3(LNA) & $21.95 \pm 3.62$ & $26.31 \pm 3.16$ & $28.19 \pm 2.57$ \\
\hline $\mathrm{C} 20: 2$ & $56.37 \pm 11.38^{b}$ & $162.88 \pm 29.35^{\mathrm{a}}$ & $183.56 \pm 26.01^{\mathrm{a}}$ \\
\hline$C 20: 3 n-6$ & $15.24 \pm 13.20^{\mathrm{b}}$ & $26.22 \pm 22.86^{\mathrm{b}}$ & $56.47 \pm 2.01^{\mathrm{a}}$ \\
\hline C20:4n-6(ARA) & $131.98 \pm 7.88$ & $118.25 \pm 42.73$ & $108.36 \pm 18.62$ \\
\hline C20:5n-3(EPA) & $104.67 \pm 19.20$ & $97.27 \pm 45.61$ & $68.35 \pm 6.63$ \\
\hline C22:6n-3(DHA) & $310.80 \pm 19.11^{\mathrm{a}}$ & $290.36 \pm 71.26^{\mathrm{a}}$ & $208.59 \pm 17.63^{b}$ \\
\hline$\sum$ SFA & $232.13 \pm 30.26$ & $269.39 \pm 128.81$ & $317.11 \pm 56.24$ \\
\hline$\sum$ MUFA & $82.88 \pm 22.09^{\mathrm{b}}$ & $122.65 \pm 28.02^{\mathrm{ab}}$ & $133.08 \pm 20.12^{\mathrm{a}}$ \\
\hline$\sum$ PUFA & $662.38 \pm 73.80$ & $860.19 \pm 249.80$ & $891.02 \pm 101.92$ \\
\hline$\sum \mathrm{n}-3$ & $126.63 \pm 22.71$ & $123.59 \pm 48.76$ & $96.55 \pm 9.19$ \\
\hline$\sum \mathrm{n}-6$ & $168.59 \pm 22.51^{b}$ & $283.37 \pm 119.75^{\mathrm{ab}}$ & $402.33 \pm 52.00^{\mathrm{a}}$ \\
\hline$\sum \mathrm{n}-3 / \sum \mathrm{n}-6$ & $0.75 \pm 0.04^{\mathrm{a}}$ & $0.44 \pm 0.03^{\mathrm{b}}$ & $0.24 \pm 0.01^{\mathrm{c}}$ \\
\hline
\end{tabular}

Values are represented as means \pm SD. Values sharing the same letters are not significantly different $(\mathrm{p}>0.05)$, whereas those with different letters are significantly different $(\mathrm{p}<0.05)$. LNA: Alpha-linolenic acid; ARA: Arachidonic acid; EPA: Eicosapentaenoic acid; DHA: Docosahexaenoic acid; $\sum$ SFA: Total saturated fatty acids; $\sum$ MUFA: Total monounsaturated fatty acids; $\sum$ PUFA: Total polyunsaturated fatty acids; - represents not detected. 


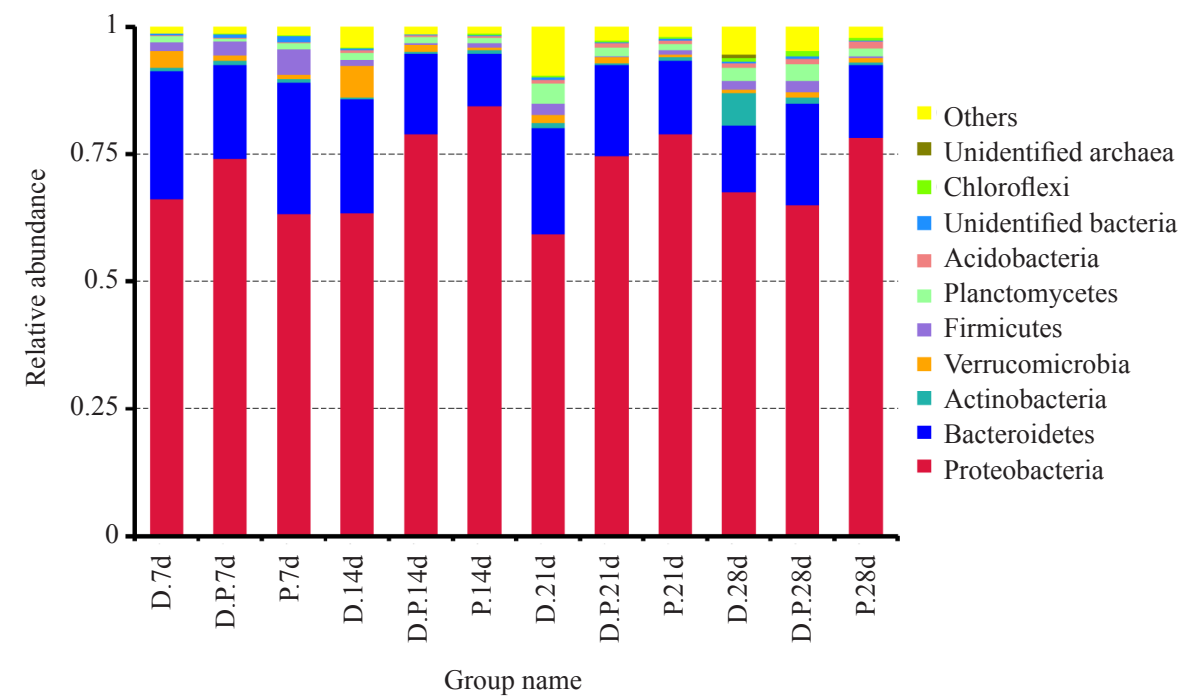

Fig. 1. Composition of the faecal microbiota at phylum level in 3 diet groups. D: Group fed with $100 \%$ D. inornate, D. P: Group fed with 50\% D. inornate and 50\% PMC replacement, P: Group fed with 100\% PMC replacement

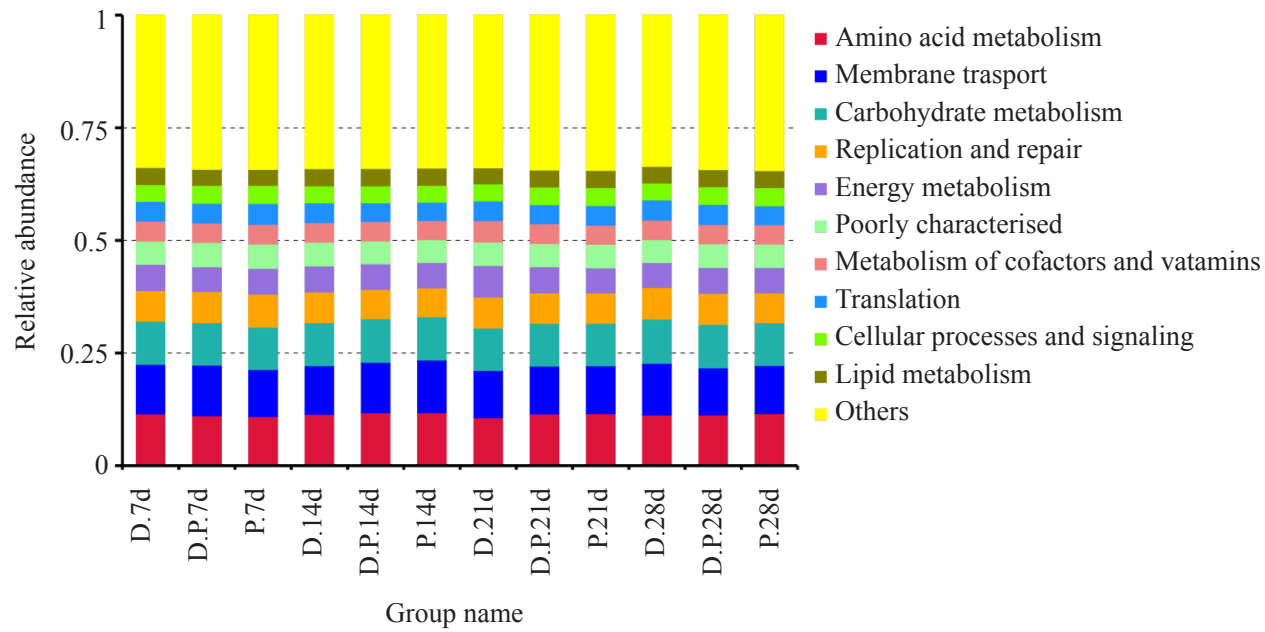

Fig. 2. Functional prediction of the faecal microbiota in 3 diet groups. D: Group fed with $100 \%$ D. inornate, D. P: Group fed with $50 \%$ D. inornate and 50\% PMC replacement, P: Group fed with 100\% PMC replacement

\section{Discussion}

Microalgae are the primary food source of bivalves in the hatcheries and considering the nutritional properties, concentrated and dried microalgae appear to be the best alternative products for bivalve juveniles particularly (Robert and Trintignac, 1997). Flagellates and diatoms with high nutritional value for some bivalve larvae or juveniles, such as Isochrysis (Liu et al., 2009), Pavlova luther (Delaunay et al., 1993) and Chaetoceros (Brown and Robert, 2002; Rivero-Rodríguez et al., 2007) are commercially reliable microalgae used in hatcheries. As compared to the monospecific microalgae, mixed microalgae diets always showed better stimulatory effects on bivalve productivity because they could complement the nutritional profile and provide balanced essential nutrients (Webb and Chu, 1983; Ragg et al., 2010). In this study, we prepared PMC added with both dried C. vulgaris and S. platensis powder. Cholrella powder has been widely used in fish feed for its advantages in aquaculture, including growth promotion, improving feeding rate and regulating innate immune defense of fish (Kim et al., 2002; Spolaore et al., 2006; Xu et al., 2014). Spirulina powder can be used as a protein substitute or functional additive in aquaculture (Ibrahem et al., 2013; Kim et al., 2013). Unlike some species of diatoms and flagellates cultured in sizeable quantities with difficulty, both Cholrella and Spirulina belong to the most utilised microalgae, which subsequently profit their commercial 
applications in the substitute diets. In aquaculture, soybean meal has the potential to be used as sustainable, low-cost protein source for its favourable amino acid profile, palatability and digestibility (Watanabe, 2002; Barnes et al., 2014). However, numerous anti-nutritional factors of soybean meal limits its use in fish diets (Iwashita et al., 2008). Heating and fermentation can reduce the amount of thermolabile antinutritional factors (Barrows et al., 2007; Teng et al., 2012). Fermented soybean meal has been suggested to be the primary protein source for some cultured fish (Yamamoto et al., 2010). In this work, fermented soybean meal was supplemented to mixed Cholrella and Spirulina powder to prepare composite algal powder.

Filter-feeding bivalves have high retaining rates for particles with diameter ranging from 1.4 to $4 \mu \mathrm{m}$, which increases with growth (Shumway et al., 1985; Tezuka et al., 2009). The larvae of $R$. philippinarum and $R$. decussatus could ingest single-cell detritus less than $20 \mu \mathrm{m}$ (Uchida and Numaguchi, 1996; Camacho et al., 2004). To facilitate intake of $R$. philippinarum juveniles, we smashed Cholrella, Spirulina powder and fermented soybean meal to particle size below $20 \mu \mathrm{m}$. Smashed microalgae powder and fermented soybean meal were added with granular sodium alginate and 2\% calcium chloride solution and then compressed to feed blocks. Sodium alginate could cross-link with calcium ions to form a gel, which helped the feed blocks slowly release nutrient substances. Our previous study has proved that the daily release of feed block was about $2 \mathrm{~g}$ dry weight under simulated natural flow conditions of seawater. In the cold season, slow-release feed blocks were suitable to be used to deal with the shortage of natural diet in the natural culture conditions. Under indoor culture conditions, without flow velocity, we scrubbed feed blocks to suitable particulate composite before feeding. When PMC replaced 50 or $100 \%$ live $D$. inornata, both mean body weight and mean shell length of juvenile clams were similar to those fed with $100 \%$ live D. inornata. In addition, replacement of 50 or $100 \%$ D. inornata with PMC did not affect survival rate of juvenile clams. From the growth performance and survival rate of the clams, it is evident that PMC could not only be ingested, digested and assimilated by juvenile clams, but also meet their nutritional requirements.

Aquatic animal growth relies heavily on the nutrient utilisation and digestive enzymes play important roles in nutrient digestion. Their activities directly reflect the digestive capacity and the nutritional status of aquatic animals (Furne et al., 2005). Not only diet size but also diet composition could affect digestive enzyme activities (Baragi and Lowell, 1986; Pedersen and Andersen, 1992). In the current study, partial or total replacement of
D. inornata with PMC did not affect amylase activity, but increased lipase and pepsin activity, suggesting there was greater difference in dietary protein and lipid than carbohydrate between PMC and D. inornata. Both lipase and pepsin activity increased with increase of PMC replacement. This further demonstrated that juvenile Manila clams have the capacity to adapt their digestive physiology in response to the changes in dietary compositions.

There were nine essential amino acids (EAA) in Manila clams, including methionine, leucine, isoleucine, lysine, phenylalanine, tyrosine, threonine, histidine and valine and the nutritional value of protein was largely determined by the content and composition of these EAA. There was no significant difference in these nine EAA contents between clams fed with $D$. inornata and PMC, indicating that total or partial replacement of $D$. inornata with PMC did not affect EAA content and composition of clams. The flavour quality of aquatic organisms mainly depends on the content of delicious amino acids (DAA) contained in their edible parts. In this study, replacing 100\% D. inornata with PMC led to significant increase in DAA contents. This indicates that PMC could improve the taste of clams and in perspective of protein nutrition, PMC was suitable to replace microgalgae as a substitute. The growth and development of bivalve larvae and post-larvae necessitates three types of long-chained polyunsaturated fatty acids (LC-PUFA); docosahexaenoic acid (DHA, 22:6n-3), eicosapentaenoic acid (EPA, 20:5n-3) and arachidonic acid (ARA, 20:4n-6) (Langdon and Waldock, 1981; Pernet et al., 2005). However, bivalves lack the ability to biosynthesize these LC-PUFA and have to depend on dietary source (Laing et al., 1990; Freites et al., 2002). In the current study, these LC-PUFA accounted for a significant proportion of PUFA in juvenile clam tissue. Such findings are consistent with previous studies (Freites et al., 2002; Pettersen et al., 2010). Replacement of 50 or $100 \%$ D. inornata with PMC did not affect ARA and EPA contents of juvenile clams, but decreased DHA contents. The results suggest that PMC could provide ARA and EPA similar to D. inornata, but with fewer DHA. With the increased replacement of PMC, DHA content of clam juveniles decreased, however, survival rate of clam juveniles decreased insignificantly. In other bivalve species, inconsistent results were found. Pettersen et al. (2010) found a distinct correlation between body DHA content and survival which showed the importance of DHA on larval health of blue mussel and Pernet and Tremblay (2004) got similar results in the sea scallop.

The gut microbiota plays an essential role in the maintenance of host health, including regulating host 
metabolism (Karasov and Carey, 2009), protecting the host from colonisation by pathogens (Quigley, 2006), enhancing gut development (Castillo et al., 2007) and stimulating development of immunity (Hrncir et al., 2008). Diet is considered a key factor that influence the gut microbiota composition (Tremaroli and Backhed, 2012). It was difficult to sample the gut of juvenile $R$. philippinarum with mean shell length of 5-6 $\mathrm{mm}$ and bacterial diversity and abundance in faeces was used to evaluate gut bacterial composition according to the previous studies (Kim et al., 2015; Han et al., 2017). R. philippinarum in 3 diet groups had similar top 10 phyla. Proteobacteria and Bacteroidetes were the first and second dominant phyla in faeces of $R$. philippinarum in the 3 diet groups. Consistent with our results, Liu et al. (2020) found Proteobacteria (39.3 -84.1\%) and Bacteroidetes (7.1-32.6\%) as the top two phyla in the gut of scallop Chlamys nobilis. Besides Proteobacteria and Bacteroidetes, $R$. philippinarum and $C$. nobilis shared the other two dominant phyla of Actinobacteria and Firmicutes. Products of intestinal bacterial metabolism acted as signaling molecules and influence the host's metabolism (Tremaroli and Backhed, 2012). In humans and other vertebrates, it has been revealed that gut microbiota produces many metabolites, including short-chain fatty acids (Immerseel et al., 2010), essential vitamins (Hill, 1997), amino acids (Mardinoglu et al., 2015) and digestive enzymes that act in conjunction with the host (Tremaroli and Backhed, 2012; Carmody and Turnbaugh, 2014). Similar relative abundance of faecal bacterial functions, especially metabolism, were observed in clams fed with or without PMC replacement. Replacement of 50 or $100 \%$ D. nornate with PMC diet for 28 days had no significant effect on the metabolic functions of gut bacteria and would not affect the host's metabolism obviously.

In conclusion, PMC is cost-effective and easy to handle in perspective of production technology and the price of ingredients. Results of the feeding experiments clearly demonstrated that partial $(50 \%)$ and total $(100 \%)$ replacement of $D$. inornata with PMC did not affect growth performance and survival rate of juvenile Manila clams. Results of evaluation of the digestive enzyme activities, amino acid and fatty acid composition and the abundance of faecal bacterial functions, clearly indicates PMC is an appropriate substitute to replace live microalgae as feed in the culture of juvenile clams.

\section{Acknowledgements}

We would like to thank Tianjin Haisheng Aquaculture Co. Ltd. for providing experimental site. We also thank Yadong Huang, Yongxiang $\mathrm{Li}$ and Xiujuan Duan in Tianjin Haisheng Aquaculture Co. Ltd. for their technical support during the work. This work was supported by the National Natural Science Foundation of China under GrantNo. 3197210095, 42076121 and 31772857; Project of Tianjin Science and Technology under Grant No. 19YFZCSN00070; Earmarked Fund for Modern Agro-Industry Technology Research System under Grant No. CARS-49; the Fundamental Research Funds of Tianjin Universities under Grant No. 2019KJ041 and 2020ZD06 and Tianjin Agricultural Science and Technology Achievements Transformation and Promotion Project under Grant No. 201903010.

\section{References}

Baragi, V. and Lovell, R. T. 1986. Digestive enzyme activities in striped bass from first feeding through larval development. Trans. Am. Fish Soc., 115(3): 478-484. https://doi. org/10.1577/1548-8659(1986)115<478:DEAISB $>2.0$. $\mathrm{CO} ; 2$.

Barnes, M. E., Brown, M. L., Bruce, T. and Sindelar, S. 2014. Rainbow trout rearing performance, intestinal morphology and immune response after long-term feeding of high levels of fermented soybean meal. N. Am. J. Aquac., 76(4): 333-345. https://doi. org/10.1080/15222055.2014.920748.

Barrows, F. T., Stone, D. A. J. and Hardy, R. W. 2007. The effects of extrusion conditions on the nutritional value of soybean meal for rainbow trout (Oncorhynchus mykiss). Aquaculture, 265(1-4): 244-252. https://doi. org/10.1016/j. aquaculture.2007.01.017.

Bi, X. D., Dai, W., Wang, X. Y., Dong, S. J., Zhang, S. L., Zhang, D. J. and Shi, H. Y. 2019. Effects of Bacillus subtilis on the growth, colony maintenance and attached bacterial community composition of colonial cyanobacteria. Environ. Sci. Pollut. Res., 26(15): 14977-14987. https:// doi. org/10.1007/s11356-019-04902-y.

Bokulich, N. A., Subramanian, S., Faith, J. J., Gevers, D., Gordon, J. I. and Knight, R. 2013. Quality-filtering vastly improves diversity estimates from Illumina amplicon sequencing. Nat. Methods, 10: 57-59. https://doi.org/10. 1038/nmeth.2276

Bradford, M. M. 1976. A rapid and sensitive method for the quantitation of microgram quantities of protein utilising the principle of protein-dye binding. Anal. Biochem., 72(1-2): 248-254. https://doi. org/10.1016/0003-2697(76)90527-3.

Brown, M. and Robert, R. 2002. Preparation and assessment of microalgal concentrates as feeds for larval and juvenile Pacific oyster (Crassostrea gigas). Aquaculture, 207(3-4): 289-309. https://doi. org/10.1016/S0044-8486(01)00742-6.

Camacho, A. P., Salinas, J. M., Fuertes, C. and Delgado, M. 2004. Preparation of single cell detritus from Laminaria saccharina as a hatchery diet for bivalve molluscs. Mar. Biotechnol., 6(6): 642-649. https://doi.org/10.1007/s1012 6-004-2901-z.

Caporaso, J. G., Kuczynski, J., Stombaugh, J., Bittinger, K., Bushman, F. D. and Costello, E. K. 2010. QIIME allows 
analysis of high-throughput community sequencing data. Nat. Methods, 7: 335-336. https://doi. org/10.1038/nmeth. f.303.

Caporaso, J. G., Lauber, C. L., Walters, W. A., Berg-Lyons, D., Lozupone, C. A. and Turnbaugh, P. J. 2011. Global patterns of 16S rRNA diversity at a depth of millions of sequences per sample. Proc. Natl. Acad. Sci. USA, 108(11Suppl.): 4516-4522. https://doi. org/10.1073/pnas.1000080107.

Carmody, R. N. and Turnbaugh, P. J. 2014. Host-microbial interactions in the metabolism of therapeutic and dietderived xenobiotics. J. Clin. Invest., 124: 4173-4181. https://doi.org/10.1172/JCI72335.

Castillo, M., Martin-Orue, S. M., Nofrarias, M., Manzanilla, E. G. and Gasa, J. 2007. Changes in caecal microbiota and mucosal morphology of weaned pigs. Vet. Microbiol., 124(3-4): 239-247. https://doi.org/10.1016/j.vetmic.2007. 04.026 .

Dai, Z. L, Wu, Z. L., Jia, S. C. and Wu, G. 2014. Analysis of amino acid composition in proteins of animal tissues and foods as pre-column o-phthaldialdehyde derivatives by HPLC with fluorescence detection. J. Chromatogr. B., 964: 116-127. https://doi. org/10.1016/j.jchromb.2014.03.025.

Delaunay, F., Marty, Y., Moal, J. and Samain, J. F. 1993. The effect of monospecific algal diets on growth and fatty acid composition of Pecten maximus (L.) larvae. J. Exp. Mar. Biol. Ecol., 173(2): 163-179. https://doi. org/ 10.1016/0022-0981(93)90051-O.

Desantis, T. Z., Hugenholtz, P., Larsen, N., Rojas, M. and Andersen, G. L. 2006. Greengenes, a chimera checked 16S rRNA gene database and workbench compatible with ARB. Appl. Environ. Microbiol., 72(7): 5069-5072. https:// doi. org/10.1128/AEM.03006-05.

Edgar, R. C. 2004. MUSCLE: Multiple sequence alignment with high accuracy and high throughput. Nucleic Acids Res., 32: 1792-1797. https://doi. org/10.2460/ajvr.69.1.82.

Edgar, R. C. 2013. UPARSE: Highly accurate OTU sequences from microbial amplicon reads. Nat. Methods, 10(10): 996-998. https://doi. org/10.1038/nmeth.2604.

Edgar, R. C., Haas, B. J., Clemente, J. C., Quince, C. and Knight, R. 2011. UCHIME improves sensitivity and speed of chimera detection. Bioinformatics, 27(16): 2194-2200. https://doi. org/10.1093/bioinformatics/btr381.

Ehteshami, F., Romano, N., Fard, E. R. and Sahafi, H .H. 2016. Effect of different dietary microalgae combinations on growth and survival of black-lip pearl oyster (Pinctada margaritifera) larvae and the feasibility of replacing microalgae with a dietary lipid emulsion. Aquac. Nutr., 23(4): 671-680. https://doi. org/10.1111/anu.12434.

Fang, J. and Lin, Z. 2016. Development of Manila clam industry in China. Bulletin of Japan Fisheries Research and Education Agency, 42: 29-34.

Freites, L., Fernandez-Reiriz, M. J. and Labarta, U. 2002. Fatty acid profiles of Mytilus galloprovincialis (Lmk) mussel of subtidal and rocky shore origin. Comp. Biochem. Phys. B., 2002, 132(2):453-461. https://doi.org/10.1016/S1096-49 59(02)00057-X.

Furne, M., Hidalgo, M. C., Lopez, A., Garcia-Gallego, M., Morales, A. E., Domezain, A. and Sanz, A. 2005. Digestive enzyme activities in Adriatic sturgeon Acipenser naccarii and rainbow trout Oncorhynchus mykiss. A comparative study. Aquaculture, 250(1-2): 391-398. https://doi.org/10. 1016/j.aquaculture.2005.05.017.

Guillard, R. R. L. 1974. Culture of phytoplankton for feeding marine invertebrates. In: Smith, W. L. and Chanley, M. H. (Eds.), Culture of marine invertebrate animals. Plenum Press, New York, USA, p. 26-60.

Haas, B. J., Gevers, D., Earl, A. M., Feldgarden, M., Ward, D. V. and Giannoukos, G. 2011. Chimeric 16S rRNA sequence formation and detection in Sanger and 454-pyrosequenced PCR amplicons. Genome Res., 21(3): 494-504. https://doi. org/10.1101/gr.112730.110.

Han, B. J., Choi, M. K., Kang, J. H., Sang, I. P. and Lee, H. J. 2017. Association of dietary patterns with the fecal microbiota in Korean adolescents. BMC Nutr., 3(20): 1-11. https://doi. org/10.1186/s40795-016-0125-z.

Hill, M. J. 1997. Intestinal flora and endogenous vitamin synthesis. Eur. J. Cancer Prevention, 6: S43-45. https://doi. org/10.1097/00008469-199703001-00009.

Hrncir, T., Stepankova, R., Kozakova, H., Hudcovic, T. and Tlaskalova-Hogenova, H. 2008. Gut microbiota and lipopolysaccharide content of the diet influence development of regulatory $\mathrm{T}$ cells: Studies in germ-free mice. BMC Immunol., 9: 65. https://doi. org/10.1186/14712172-9-65.

Huo, Z. M., Li, Y., Rbbani, M. G., Wu, Q. and Yan, X. 2018. Temperature challenge on larvae and juveniles of the Manila clam Ruditapes philippinarum. Aquac. Res., 49(4): 1727-1731. https://doi. org/10.1111/are.13600.

Ibrahem, M. D., Mohamed, M. F. and Ibrahim, M. A. 2013. The role of Spirulina platensis (Arthrospira platensis) in growth and immunity of Nile tilapia (Oreochromis niloticus) and its resistance to bacterial infection. J. Agr. Sci., 5(6): 109-117. https://doi. org/10.5539/jas.v5n6p109.

Immerseel, V. F., Ducatelle, R., Vos, M. D., Boon, N., Wiele, T. V. D. and Verbeke, K. 2010. Butyric acid-producing anaerobic bacteria as a novel probiotic treatment approach for inflammatory bowel disease. J. Med. Microbiol., 59: 141-143. https://doi. org/10.1099/jmm.0.017541-0.

Iwashita, Y., Yamamoto, T., Furuita, H., Sugita, T. and Suzuki, N. 2008. Influence of certain soybean antinutritional factors supplemented to a casein-based semi purified diet on intestinal and liver morphology in fingerling rainbow trout Oncorhynchus mykiss. Fish. Sci., 74(5): 1075-1082. https:// doi. org/10.1111/j.1444-2906.2008.01627.x. 
Karasov, W. H. and Carey, H. V. 2009. Metabolic teamwork between gut microbes and hosts. Microbe, 4(7): 323-328. https://doi.org/10.1128/microbe.4.323.1.

Kim, M., Kim, J., Kuehn, L. A., Bono, J. L., Berry, E., Kalchayanand, N., Freetly, H. C., Benson, A. K. and Wells, J. E. 2015. Investigation of bacterial diversity in the feces of cattle fed different diets. J. Agr. Sci., 92(2): 683-94. https://doi.org/10.2527/jas.2013-6841.

Kim, K. W., Bai, S. C., Koo, J. W., Wang, X. and Kim, S. K. 2002. Effects of dietary Chlorella ellipsoidea supplementation on growth, blood characteristics and whole-body composition in juvenile Japanese flounder Paralichthys olivaceus. J. World Aquac. Soc., 33(4): 425-431. https://doi.org/10. 1111/j.1749-7345.2002.tb00021.x.

Kim, S. S., Rahimnejad, S., Kim, K. W. and Lee, K. J. 2013. Partial replacement of fish meal with Spirulina pacifica in diets for parrot fish (Oplegnathus fasciatus). Turk. J. Fish. Aquat. Sci., 13: 197-204. https://doi.org/10.4194/13032712-v13_2_01.

Laing, I., Child, A. R. and Janke, A. 1990. Nutritional value of dried algae diets for larvae of Manila clam (Tapes philippinarum). J. Mar. Biol. Ass. UK., 70(1): 1-12.

Langdon, C. J. and Waldock, M. J. 1981. The effect of algal and artificial diets on the growth and fatty acid composition of Crassostrea gigas spat. J. Mar. Biol. Ass. UK., 61(2): 431-448. https://doi. org/10.1017/S0025315400047056.

Liang, J., Huo, Z. M., Guo, Y. J., Li, Y. and Yan, X. 2019. Mass selection for fast growth in the third generation of the orange line of the manila clam Ruditapes philippinarum. J. Ocean Univ. China, 18(6): 1481-1485. https://doi. org/10.1007/ s11802-019-4029-9.

Liu, W., Pearce, C. M., Alabi, A. O. and Gurney-Smith, H. 2009. Effects of microalgal diets on the growth and survival of larvae and post-larvae of the basket cockle, Clinocardium nuttallii. Aquaculture, 293(3-4): 248-254. https://doi. org/10.1016/j.aquaculture.2009.04.032.

Magoc, T. and Salzberg, S. L. 2011. FLASH: fast length adjustment of short reads to improve genome assemblies. Bioinformatics, 27(21): 2957-2963. https://doi.org/10.1093 /bioinformatics/btr507.

Mardinoglu, A., Shoaie, S., Bergentall, M., Ghaffari, P., Zhang, C. and Larsson, E. 2015. The gut microbiota modulates host amino acid and glutathione metabolism in mice. Mol. Syst. Biol., 11(10): 834. https://doi.org/10.15252/msb.20156487.

Pedersen, B. H. and Andersen, K. P. 1992. Induction of trypsinogen secretion in herring larvae (Clupea harengus). Mar. Biol., 112(4): 559-565. https://doi.org/10.1007/BF 00346173.

Pernet, F., Bricelj, V. M. and Parrish, C. C. 2005. Effect of varying dietary levels of $\omega 6$ polyunsaturated fatty acids during the early ontogeny of the sea scallop, Placopecten magellanicus. J. Exp. Mar. Biol. Ecol., 327(2): 115-133. https://doi.org/10.1016/j.jembe.2005.06.008.
Pernet, F. and Tremblay, R. 2004. Effect of varying levels of dietary essential fatty acid during early ontogeny of the sea scallop Placopecten magellanicus. J. Exp. Mar. Biol. Ecol., 310(1): 73-86. https://doi.org/10.1016/j.jembe.2004. 04.001 .

Pettersen, A. K., Turchini, G. M., Jahangard, S., Ingram, B. A. and Sherman, C. D. H. 2010. Effects of different dietary microalgae on survival, growth, settlement and fatty acid composition of blue mussel (Mytilus galloprovincialis) larvae. Aquaculture, 309(1-4): 115-124. https://doi.org/ 10.1016/j.aquaculture.2010.09.024.

Ponis, E., Parisi, G., Zittelli, G. C., Lavista, F., Robert, R. and Tredici, M. R. 2008. Pavlova lutheri: Production, preservation and use as food for Crassostrea gigas larvae. Aquaculture, 282(1-4): 97-103. https://doi.org/10.1016/j. aquaculture.2008.06.010.

Quigley, E. M. M. 2006. New perspectives on the role of the intestinal flora in health and disease. J. Gast. Liver, 15(2): 109-110.

Ragg, N. L. C., King, N., Watts, E. and Morrish, J. 2010. Optimising the delivery of the key dietary diatom Chaetoceros calcitrans to intensively cultured Greenshell (TM) mussel larvae, Perna canaliculus. Aquaculture, 306(1): 270-280. https://doi.org/10.1016/j.aquaculture. 2010.05.010.

Rivero-Rodríguez, S., Beaumont, A. R. and Lora-Vilchis, M. C. 2007. The effect of microalgal diets on growth, biochemical composition and fatty acid profile of Crassostrea corteziensis (Hertlein) juveniles. Aquaculture, 263(1-4): 199-210. https://doi.org/10.1016/j.aquaculture. 2006.09.038.

Robert, R. and Trintignac, P. 1997. Substitutes for live microalgae in mariculture: A review. Aquat. Living Resour., 10(5): 315-327. https://doi.org/10.1051/alr:1997035.

Shumway, S. E., Cucci, T. L., Newell, R. C. and Yentch, C. M. 1985. Particle selection, ingestion, and absorption in filter-feeding bivalves. J. Exp. Mar. Biol. Ecol., 91(1-2): 77-92. https://doi.org/10.1016/0022-0981(85)90222-9.

Spolaore, P., Joannis-Cassan, C., Duran, E. and Isambert, A. 2006. Commercial applications of microalgae. J. Biosci. Bioeng., 101(2): 87-96. https://doi.org/10.1263/jbb.101.87.

Tanyaros, S., Sujarit, C., Jansri, N. and Tarangkoon, W. 2016. Baker's yeast as a substitute for microalgae in the hatchery rearing of larval and juvenile tropical oyster (Crassostrea belcheri, Sowerby 1871). J. Appl. Aquac., 28(1): 35-46. https://doi. org/10.1080/10454438.2016.1163312.

Teng, D., Meiyun, G., Yang, Y., Liu, B., Tian, Z. and Wang, J. 2012. Biomodification of soybean meal with Bacillus subtilis or Aspergillus oryzae. Biocatalysis and Agricultural Biotechnology, 1(1): 32-38. https://doi.org/10.1016/j.bcab. 2011.08.005.

Tezuka, N., Ichisaki, E., Kanematsu, M., Usuki, H., Hamaguchi, M. and Iseki, K. 2009. Particle retention efficiency of asari clam Ruditapes philippinarum larvae. Aquat. Biol., 6(1-3): 281-287. 
Tremaroli, V. and Backhed, F. 2012. Functional interactions between the gut microbiota and host metabolism. Nature, 489: 242-249. https://doi.org/10.3354/ab00132.

Uchida, M. and Numaguchi, K. 1996. Formation of protoplasmic detritus with characteristics favorable as food for secondary animals during microbial decomposition of Ulva pertusa (Chlorophyta) frond. J. Mar. Biotechnol., 4(4): 200-206.

Wang, Q., Garrity, G. M. and Tiedje, J. M. 2007. Naive Bayesian classifier for rapid assignment of rRNA sequences into the new bacterial taxonomy. Appl. Environ. Microbiol., 73: 5261-5267. https://doi.org/10.1128/AEM.00062-07.

Watanabe, T. 2002. Strategies for further development of aquatic feeds. Fish. Sci., 68: 242-252. https://doi.org/10.1046/ j.1444-2906.2002.00418.x.

Webb, K. L. and Chu, F. E. 1983. Phytoplankton as a food source for bivalve larvae. In: Gary, D. Pruder, Christopher, J. Langdon, Douglas, E. Conklin (Eds.), Proceedings of the Second International Conference on Aquaculture Nutrition: Biochemical and Physiological Approaches to Shellfish Nutrition, 27-29 October 1981, Delaware, USA, p. 272-291.

Willer, D. and Aldridge, D. C. 2017. Microencapsulated diets to improve bivalve shellfish aquaculture. R. Soc. Open Sci., 4(11): 171142. https://doi.org/10.1016/j.gfs.2019.04.007.
Xu, W., Gao, Z., Qi, Z., Qiu, M., Peng, J. Q. and Shao, R. 2014. Effect of dietary chlorella on the growth performance and physiological parameters of gibel carp, Carassius auratus gibelio. Turk. J. Fish Aquat. Sci., 14(1): 53-57. https://doi. org/10.4194/1303-2712-v14_1_07.

Yamamoto, T., Iwashita, Y., Matsunari, H., Sugita, T., Furuita, H., Akimoto, A., Okamatsu, K. and Suzuki, N. 2010. Influence of fermentation conditions for soybean meal in a non-fish meal diet on the growth performance and physiological condition of rainbow trout Oncorhynchus mykiss. Aquaculture, 309(1-4): 173-180. https://doi. $\operatorname{org} / 10.1016 /$ j.aquaculture.2010.09.021.

Yin, X. W., Wang, J. J., Yang, M. and Xie, X. 2019. Evaluation of macroalgal detritus as food source for juvenile Manila clam, Ruditapes philippinarum: Effects on growth, amino acid content and fatty acid composition. Aquac. Res., 00: 1-10. https://doi.org/10.1111/are.14313.

Yu, X. J., Xu, L. J. and Liu, X. Z. 2020. China fishery statistical yearbook. China Agricultural Press, Beijing, China, p. 22-24. (in Chinese).

Zhang, G. F. and Yan, X. W. 2006. Development of a new three-phases culture method for Manila clam Ruditapes philippinarum, farming in northern China. Aquaculture, 258(1-4): 452-461. https://doi.org/10.1016/j. aquaculture.2006.04.046. 